\title{
COMENTÁRIOS AO ARTIGO "A 'POLÍTICA DOS TERREIROS' CONTRA O RACISMO RELIGIOSO E AS POLÍTICAS 'CRISTOFASCISTAS'”, DE ANA PAULA MIRANDA ${ }^{1}$
}

\section{Ronaldo de Almeida ${ }^{2}$}

Resumo: Trata-se de comentários ao artigo de Ana Paula Miranda sobre o deslocamento da categoria de acusação "intolerância religiosa" para a de "racismo religioso" no discurso do movimento de terreiros em defesa das religióes afro-brasileiras. No primeiro comentário, tematizo as noçóes de liberdade de expressão e liberdade religiosa. No segundo, trato do jogo ambíguo de segmentos evangélicos entre se considerar uma "minoria perseguida" e, simultaneamente, afirmar-se como "maioria cristâ". Por fim, reflito como a sobreposição das violências criminal, religiosa e racial tornaram o termo intolerância religiosa insuficiente para compreender a realidade atual dos conflitos religiosos.

Palavras-chave: intolerância religiosa; racismo religioso; liberdade de expressão; maioria cristá. RACISM AND 'CHRISTOFASCIST' POLITICS”, BY ANA PAULA MIRANDA

Abstract: These are comments on Ana Paula Miranda's article about the displacement of the accusation category "religious intolerance" to that of "religious racism" in the discourse of the movement of terreiros in defense of Afro-Brazilian religions. In the first comment, I discuss the notions of free speech and religious freedom. In the second, I deal with the ambiguous game of evangelical segments between considering themselves a "persecuted minority" and, simultaneously, affirming

1 Como citar: ALMEIDA, Ronaldo. Comentários ao artigo "A 'política dos terreiros' contra o racismo religioso e as políticas 'cristofascistas'”, de Ana Paula Miranda. Debates do NER, Porto Alegre, ano 21, n. 40, p. 185-192, 2021.

2 Doutor em Antropologia Social, professor do Departamento de Antropologia da Universidade Estadual de Campinas e pesquisador do Centro Brasileiro de Análise e Planejamento, Brasil. E-mail: ronaldormalmeida@gmail.com. ORCID: https://orcid.org/0000-0001-8143-6671. 
themselves as a "Christian majority". Finally, I reflect on how the overlapping of criminal, religious, and racial violence has made the term religious intolerance insufficient to understand the current reality of religious conflicts.

Keywords: religious intolerance; religious racism; free speech; christian majority

Como entender o deslocamento da categoria de acusação "intolerância religiosa" para a de "racismo religioso" no discurso do movimento de terreiros em defesa das religióes afro-brasileiras? O artigo de Ana Paula Miranda reflete sobre as mutaçóes recentes da reação das afro-religióes às agressóes simbólicas, materiais e físicas sofridas, notadamente aquelas perpetradas por parcelas de igrejas e fiéis neopentecostais.

As agressóes não se reduzem a um suposto âmbito do religioso, mas estão articuladas a outros "problemas públicos" do Brasil: crime, domínio de territórios, pobreza urbana, desigualdade social, conflito racial etc. Daí o deslocamento estratégico da política dos terreiros ao tratar as agressóes como racismo religioso. Amplia-se, desta forma, o léxico de categorias e a disputa pela nomeação do conflito: intolerância, racismo ou genocídio. Como sugere Butler (2015), procura-se estabelecer um outro enquadramento conforme as mutaçóes dos atores e das relaçóes entre forças sociais e políticas. Para tanto, a "política dos terreiros" busca construir, por meio da racialização, o reconhecimento de sujeitos de direitos, tendo a criminalização e a vitimização como motores da mobilização.

Ciente da complexidade dos conflitos religiosos no Brasil atual, faço três comentários à análise de Miranda a partir de questôes relativas propriamente aos agressores da violência religiosa (alguns evangélicos).

1. Começo puxando o fio da meada pelo apelo de setores evangélicos conservadores às noçóes de liberdade de expressão e liberdade religiosa

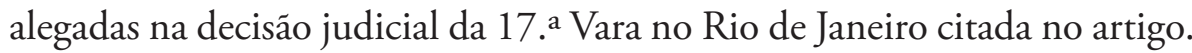
Segundo o veredicto - além de considerar que as religiôes afro-brasileiras não são religião -, o vilipêndio simbólico imposto a elas pela Igreja Universal do Reino de Deus não poderia sofrer a censura do Estado por estar no âmbito da liberdade de expressão garantida pela liberdade religiosa. 
O artigo de Miranda não trata da pandemia de Covid-19, mas o tema da liberdade também foi recentemente mobilizado judicialmente contra o fechamento temporário dos templos por determinaçáo de prefeitos e governadores em função da crise sanitária. A controvérsia foi decidida pelo Supremo Tribunal Federal (STF), e a argumentação jurídica dos que defendiam a abertura dos templos (basicamente formada por setores evangélicos conservadores) ancorava-se no princípio constitucional da liberdade de culto. Já no debate mais público, a controvérsia se desdobrou ainda em duas outras linhas de justificativa: a) o entendimento de que os templos religiosos deveriam ser compreendidos como "serviço essencial" para a população em situaçóes de crise sanitária; e b) o argumento de que o fechamento seria uma forma de perseguição religiosa, sobretudo, contra a uma suposta minoria evangélica.

Tanto no caso das agressóes ao Candomblé e Umbanda como no do fechamento dos templos, apelou-se a uma noção de liberdade que se legitimaria pelas convicçóes dos indivíduos e das comunidades religiosas, mesmo se elas provocarem prejuízo a outros, seja moral, psíquico ou físico. Acertadamente, a "política dos terreiros" compreendeu - à semelhança da crítica de Talal Asad (2003) ao secularismo - que as concepçôes de liberdade são referenciadas pela ideologia liberal e pelo cristianismo, o que, na história do Brasil de maioria (ainda) católica, é do interesse, sobretudo, dos protestantes históricos e dos pentecostais.

2. "Primo-irmão" do apelo à liberdade religiosa feita por evangélicos conservadores é o jogo ambíguo entre se considerar uma "minoria perseguida" e, simultaneamente, afirmar-se como "maioria cristâ", oscilando conforme o contexto da disputa.

No primeiro caso, apela-se com frequência à condição de minoria demográfica. O discurso é de que a "minoria evangélica" estaria sofrendo perseguição no país. Contudo, na verdade, a ideia de minoria evangélica é cada vez menos plausível no Brasil, que tem se tornado religiosamente mais plural desde os anos 1980. Um pluralismo confessional, parcialmente competitivo e concorrencial, e predominantemente cristáo (Camurça, 2017; 
Almeida, 2009; Pierucci, 2006a). Mas tudo se passa como se a minoria evangélica estivesse sendo cerceada pelo Estado ou submetida ao privilégio dado ao catolicismo, sem admitir que algumas de suas práticas estão acima da iconoclastia razoável própria de uma sociedade plural.

Como já advertiu Pierucci (1996) ao analisar o episódio do "chute na santa”" aquele que bate na cabeça do umbandista com uma Bíblia é quem reivindica estar sendo perseguido por sua fé. Ele denominou esta contradição como efeito de retorsáo: isto é, acusar o outro daquilo que, na verdade, você está fazendo. Um bom exemplo foi o discurso do presidente Jair Bolsonaro na Abertura Anual da ONU, em 2020, quando fez o apelo pela liberdade religiosa e pelo combate à cristofobia, como se o cristianismo sofresse alguma ameaça no Brasil e não fossem parcelas dele (principalmente o neopentecostalismo) os principais perpetradores da violência religiosa contra as afro-religióes; estas sim são historicamente as mais perseguidas.

Entretanto, no mesmo discurso, Bolsonaro declarou também que $O$ Brasil é um país cristão e conservador e tem na família sua base. Neste segundo caso, portanto, reivindica-se a condição de maioria cristã quando se trata de propor padróes morais e comportamentais restritivos da diversidade dos modos e concepçóes de vida. E para configurarem discursivamente como a maioria cristã, evangélicos e católicos são somados via conservadorismo.

Para compreender esta flutuação entre os discursos de minoria e maioria, recorri à distinção entre igreja e seita de Ernest Troelstch (1987), também adotada por Weber. A primeira, a igreja, é uma instituição coextensiva à ordem social - como a quase coincidência de ser brasileiro e ser católico no Brasil de 40 anos atrás - enquanto a segunda, a seita, implica a ruptura com os vínculos religiosos herdados por laços tradicionais (familiares, étnicos ou nacionais) e, ato contínuo, a filiação a uma congregação de fiéis em termos puramente religiosos (Pierucci, 2006b). Sugeri, assim, pensar a beligerância

3 Quando um pastor da Igreja Universal chutou a imagem de Nossa Senhora Aparecida em um programa religioso da TV Record, em 12 de outubro de 1995, dia da Padroeira do Brasil (Almeida, 2009). 
dos que se intitulam "maioria cristâ" como uma espécie de sectarismo de maioria (Almeida, 2007; 2020). Em outras palavras: uma pretensão de hegemonia cultural que visa a mudança da ordem moral e a restrição da diversidade de modos e concepçôes de vida. Não se trata de tornar a religião de setores evangélicos coextensiva à ordem social, mas, inversamente, converter esta àquela, cuja concepçáo de democracia baseia-se mais no postulado da vontade da maioria do que no da proteçáo das minorias.

3. O episódio "chute na santa", citado acima, é bastante indicativo do nível de belicosidade dos conflitos religiosos no Brasil em meados dos anos 1990: a iconoclastia de objetos fora dos seus lugares de culto. O livro de Vagner Gonçalves, publicado em 2007, ofereceu um quadro variado das intolerâncias religiosas até aquele momento. Miranda, em um momento do artigo, cita criticamente a interpretaçáo de Luiz Eduardo Soares, em 1993, antes do "chute na santa", segundo a qual os conflitos religiosos que emergiram com o neopentecostalismo poderiam contribuir para uma cultura democrática, como decorrência do pluralismo religioso e a perda de hegemonia do catolicismo. A crítica é certeira, mas em defesa de Soares, em 2019, ele recuou daquela posiçáo dos anos 1990 frente à belicosidade dos conflitos religiosos e à hegemonia política de parcelas hegemônicas do meio evangélico nas últimas três décadas (Soares, 2019).

Atualmente, as situaçôes são de destruiçâao dos lugares de culto e de ameaça de morte de lideranças religiosas por parte de traficantes identificados como evangélicos. Já em final dos anos 1990, quando se observava em campo que a conversão evangélica era uma alternativa ou possibilidade de saída de jovens do tráfico de drogas, Clara Mafra (1998) lançou a hipótese, no plano teórico, de uma semelhança, uma possível afinidade, entre o discurso do tráfico e o discurso evangélico. A tese de doutorado de Christina Vital, em 2009, transformada em livro posteriormente, foi um dos primeiros trabalhos a etnografar empiricamente esta relação entre tráfico e evangélicos.

Considero este um dos fenômenos contemporâneos mais impressionante do começo deste século. Na verdade, trata-se de um espectro variado de conexôes territorialmente localizadas: evangélico versus traficante; evangélico

Debates do NER, Porto Alegre, ANo 2I, N. 4O, P. I8 5-I92, AGo./Dez. 202 I 
ex-traficante; traficante ex-evangélico; ora evangélico ora traficante; e....evangélico traficante. Nestas interfaces, diferentes regimes de moralidade são ajustados e adotados. Essas conexôes com o crime se aprofundaram mais recentemente e a dimensão da violência religiosa foi encampada pelo tráfico contra terreiros de regióes do Rio de Janeiro pobres e com predominância de negros. Enfim, sobrepuseram-se, desta forma, as violências criminal, religiosa e racial, o que, por consequência, tornou o termo intolerância insuficiente.

Mas como adverte Miranda, não é possível identificar uma agenda comum entre esses grupos que compóem o universo de evangélicos no país. Isto posto, fica a pergunta: até onde vai a afinidade entre os discursos e em que nível ocorre a cumplicidade silenciosa de igrejas com criminosos e as parcerias nos negócios do tráficos? Da mesma forma, como compreender os Gladiadores do Altar da Igreja Universal do Reino de Deus citados no artigo: jovens que receberam treinamentos militares e fizeram performances militares-religiosas durante cultos da igreja? O episódio teve uma péssima repercussão midiática por ser associado à cultura miliciana disseminada no Rio de Janeiro, e foi abandonado posteriormente pela instituição. Há muito o que analisar da performance e da estética dos Gladiadores do Altar, mas qual a extensão, ou sobreposição, dos vínculos com os interesses e ações de milicianos?

Por fim, se raça é relação, como tratar a violência religiosa como racista quando praticada por traficantes evangélicos que também agenciam um discurso de vítima "do sistema" e do racismo da sociedade brasileira? Ou a violência de alguns evangélicos pentecostais que, na verdade, são mais pretos do que os afro-religiosos tanto em termos absolutos como relativos (Almeida, Barbosa, 2018). Diferente da realidade dos supremacistas brancos norte-americanos e europeus, como citada no artigo, a branquitude evangélica brasileira não se encontra na cor de sua pele. Os diversos sujeitos (neopentecostais, afro-religiosos e traficantes) que vivem em um mesmo território e são igualmente pobres e pretos colocam outras dobras para o entendimento do racismo religioso nestes contextos.

Excelentes pesquisas empíricas foram citadas no artigo e já oferecem um quadro variado das indagaçóes que me surgiram da leitura de Miranda. 
E dada a intensa dinâmica social, o artigo confirma também a convicção de que o investimento etnográfico contínuo, aprofundado e comparativo é a grande aposta para construir um panorama amplo de certas transformaçóes recentes da sociedade brasileira e das estratégias de ação política das religiôes em situação de conflito.

\section{REFERÊNCIAS}

ALMEIDA, Ronaldo. Evangélicos à direita. Horizontes Antropológicos, UFRGS, Porto Alegre, v. 26, p. 419-436, 2020.

ALMEIDA, Ronaldo. A Igreja Universal e seus demônios. São Paulo: Terceiro Nome, 2009.

ALMEIDA, Ronaldo. Dez anos do 'chute na santa: a intolerância com a diferença”" In: Silva, Vagner Gonçalves da. (org.). Intolerância religiosa: impactos do neopentecostalismo no campo religioso afro-brasileiro. São Paulo: Edusp, 2007.

ALMEIDA, Ronaldo; BARBOSA, Rogério. Religious Transtion in Brazil. In: Arretche, Marta. (org.). Paths of inequality in Brazil: a half-century of changes. 1 ed. Cham: Springer, v. 1, p. 257-284, 2018.

ASAD, Talal. Formations of the Secular: Christianity, Islam, Modernity, Stanford: Stanford University Press, 2003.

BUTLER, Judith. Quadros de guerra: quando a vida é passível de luto? Rio de Janeiro: Civilização Brasileira, 2015.

CAMURÇA, Marcelo. A questão da laicidade no Brasil: mosaico de configuraçóes e arena de controvérsias. Horizonte: revista de Estudos de Teologia e Ciências da Religião, v. 15, p. 855-886, 2017.

MAFRA, Clara. Drogas e símbolos: redes de solidariedade em contextos de violência. In: ALVITO, Marcos; ZALUAR, Alba (org.). Um século de favela. Rio de Janeiro: FGV, 1998. 
MIRANDA, Ana Paula Mendes de. A "política dos terreiros" contra o racismo religioso e as políticas "critofascistas". Debates do NER, Porto Alegre, ano 21, n. 40, 2021.

PIERUCCI, Antônio Flávio de Oliveira. Liberdade de cultos na sociedade de serviços: Em defesa do consumidor religioso. Novos Estudos CEBRAP, São Paulo, v. 44, p. 3-11, 1996.

PIERUCCI, Antônio Flávio de Oliveira. Cadê nossa diversidade religiosa? - comentários ao texto de Marcelo Camurça. In: TEXEIRA, Faustino; MENEZES, Renata (org.). As religiöes no Brasil: continuidades e rupturas. Petrópolis: Vozes, 2006a. p. 17-34.

PIERUCCI, Antônio Flávio de Oliveira. Religiáo como solvente - uma aula. Novos Estudos, Cebrap, São Paulo, n. 75, 2006b. p. 111-127.

SOARES, Luiz Eduardo. Revoluçôes no campo religioso. Novos Estudos, v. 38, n. 1, jan./abr., São Paulo, Cebrap, 2019. p. 85-107.

SOARES, Luiz Eduardo. Dimensóes democráticas do conflito religioso no Brasil: a guerra dos pentecostais contra o afro-brasileiro. In: Os dois corpos do presidente e outros ensaios. Rio de Janeiro: Relume Dumará, 1993.

VITAL DA CUNHA, Christina. Evangélicos em ação nas favelas cariocas: um estudo socioantropológico sobre redes de proteção, tráfico de drogas e religião no complexo de Acari. 2009. Tese (Doutorado em Ciências Sociais) - Universidade Estadual do Rio de Janeiro, Rio de Janeiro, 2009.

TROELTSCH, Ernest. Igreja e seitas. Religiāo \& Sociedade, Rio de Janeiro: Iser, v. 14, n. 3, 1987.

Recebido em: 15/07/2021

Aprovado em: 15/07/2021 